BMJ Open

Diabetes

Research

\& Care

\section{Tissue inhibitor matrix metalloproteinase 1 and risk of type 2 diabetes in a Chinese population}

To cite: Wang Y, Yuan J-M, Pan A, et al. Tissue inhibitor matrix metalloproteinase 1 and risk of type 2 diabetes in a Chinese population. BMJ Open Diab Res Care 2020;8:e001051. doi:10.1136/ bmjdrc-2019-001051

AP and W-PK are joint senior authors.

Received 14 November 2019 Revised 18 March 2020 Accepted 24 March 2020

\section{Check for updates}

(c) Author(s) (or their employer(s)) 2020. Re-use permitted under CC BY-NC. No commercial re-use. See rights and permissions. Published by BMJ.

${ }^{1}$ Health Services and Systems Research, Duke-NUS Medical School, Singapore

2UPMC Hillman Cancer Center, University of Pittsburgh,

Pittsburgh, Pennsylvania, USA ${ }^{3}$ Department of Epidemiology, Graduate School of Public Health, University of Pittsburgh, Pittsburgh, Pennsylvania, USA ${ }^{4}$ Department of Epidemiology and Biostatistics, School of Public Health, Tongji Medical College, Huazhong University of Science and Technology, Wuhan, China

${ }^{5}$ Saw Swee Hock School of Public Health, National University of Singapore, Singapore

Correspondence to Professor An Pan; panan@hust.edu.cn and Professor Woon-Puay Koh; woonpuay.koh@duke-nus. edu.sg

\section{ABSTRACT}

Introduction The non-invasive enhanced liver fibrosis (ELF) score-comprising tissue inhibitor of matrix metalloproteinases-1 (TIMP1), hyaluronic acid (HA) and amino-terminal propeptide of type III procollagen (PIIINP) has been shown to accurately predict fibrosis stages among patients with non-alcoholic fatty liver disease (NAFLD). However, no study has examined whether the ELF score or its components would also be predictive of type 2 diabetes, which commonly coexists and shares the same pathogenic abnormalities with NAFLD. Therefore, we prospectively investigated their associations with type 2 diabetes risks for the first time.

Research design and methods The ELF score was measured among 254 type 2 diabetes cases and 254 age-matched and sex-matched controls nested within the prospective Singapore Chinese Health Study. Cases had hemoglobin $\mathrm{A} 1 \mathrm{c}(\mathrm{HbA} 1 \mathrm{c})$ levels $<6.5 \%$ at blood collection (1999-2004) and reported to have diabetes during followup II (2006-2010). Controls had HbA1c levels $<6.0 \%$ at blood-taking and remained free of diabetes at follow-up II. Multivariable conditional logistic regression models were used to assess the ELF-diabetes association.

Results Higher TIMP1 levels were associated with increased type 2 diabetes risk, and the OR comparing the highest versus lowest quartiles was $2.56(95 \% \mathrm{Cl} 1.23$ to 5.34 ; $p$ trend=0.035). However, ELF score, PIIINP and HA were not significantly associated with type 2 diabetes risks.

Conclusions Higher TIMP1 levels, but not ELF score, PIIIMP and $\mathrm{HA}$, were associated with increased type 2 diabetes risk in Chinese adults. Our results suggested that elevated TIMP1 levels may contribute to the type 2 diabetes development through pathways other than liver fibrosis.

\section{INTRODUCTION}

Liver, a vital organ in maintaining glucose homeostasis, has been suggested to play an important role in the development of type 2 diabetes (T2D). ${ }^{1}$ The non-invasive enhanced liver fibrosis (ELF) score-comprising tissue inhibitor of matrix metalloproteinases-1 (TIMP1), hyaluronic acid (HA) and aminoterminal propeptide of type III procollagen (PIIINP)- has been shown to accurately diagnose advanced liver fibrosis ${ }^{2}$ and predict fibrosis stages $^{3}$ among patients with nonalcoholic fatty liver disease (NAFLD). The National Institute for Health and Care

\section{Significance of this study}

What is already known about this subject?

- The enhanced liver fibrosis (ELF) score-comprising tissue inhibitor of matrix metalloproteinases-1 (TIMP1), hyaluronic acid (HA) and amino-terminal propeptide of type III procollagen (PIIINP)—could accurately diagnose advanced liver fibrosis and predict fibrosis stages among patients with non-alcoholic fatty liver disease (NAFLD).

What are the new findings?

- Despite the fact that NAFLD and type 2 diabetes (T2D) commonly coexist and share the pathogenic abnormalities of excess adiposity and insulin resistance, ELF score was not associated with incident T2D among Chinese.

- Among the three ELF components, TIMP1 was positively associated with incident T2D, while HA and PIIINP were not associated.

How might these results change the focus of research or clinical practice?

- From the perspective of research, our results contributed to the elucidation of underlying mechanism that elevated TIMP1 levels may contribute to the development of T2D through pathways other than liver fibrosis.

- From the perspective of clinical practice, our results implied that TIMP1 may serve as a useful blood biomarker to predict the risk of developing T2D, or as a target for the prevention and treatment of T2D.

Excellence recently recommended to use the ELF score to test for and monitor advanced liver fibrosis in people diagnosed with NALFD. ${ }^{4}$ Since NAFLD and T2D commonly coexist and share the pathogenic abnormalities of excess adiposity and insulin resistance, ${ }^{5}$ we aimed to examine the prospective association between ELF score and incident T2D risk for the first time.

\section{METHODS}

The Singapore Chinese Health Study recruited 63257 Chinese men and women (aged 45-74 years) with informed consent 
between 1993 and 1998. ${ }^{6}$ At baseline, a structured questionnaire was used during a face-to-face interview to collect information on medical history, diet and lifestyle habits. Blood specimens were collected from 32535 participants at follow-up I (1999-2004), and serum was extracted and stored at $-80^{\circ} \mathrm{C}$. After a mean follow-up of 4 years, 292 participants with hemoglobin A1c (HbA1c) levels $<6.5 \%$ at blood-taking and free of diabetes reported to have physician-diagnosed diabetes during follow-up II (2006-2010), and were designated as incident T2D cases. Controls were randomly selected from those who had donated blood specimens, had HbA1c levels $<6.0 \%$ at blood-taking and remained free of diabetes at follow-up II. Cases and controls were matched on a 1:1 ratio for age ( \pm 3 years), sex (men, women), date of blood collection ( \pm 6 months) and dialect group (Cantonese, Hokkien). After excluding those with insufficient serum sample $(\mathrm{n}=37)$ or extreme ELF score $(>3 \mathrm{SD}, \mathrm{n}=1), 254$ casecontrol pairs were included for the current analysis. Informed consent was provided and completed at the baseline interview.

Using the stored serum, the ELF score was measured from the same case-control pair in the same batch, using two-site sandwich assays (Siemens ADVIA Centaur XP system) at the National University Hospital Reference Laboratory, Singapore. In terms of other blood biomarkers, gamma-glutamyl transferase and alanine aminotransferase were measured using enzymatic method (Beckman Coulter, USA). High-density lipoprotein cholesterol, triglycerides and high-sensitivity $\mathrm{C}$ reactive protein were assayed by colorimetric method (Beckman Coulter). In addition, adiponectin was measured using sandwich ELISA method and HbAlc by cation exchange HPLC (Bio-Rad Laboratories, USA). The ELF score was calculated using the following equation: $\quad \mathrm{ELF} \quad$ score $=2.278+0.851 \times \ln (\mathrm{HA})+0.751 \times 1-$ $\mathrm{n}($ PIIINP $)+0.394 \times \ln ($ TIMP1). The levels of ELF score and three components were expressed as median (range).

Multivariable conditional logistic regression models were used to compute the OR and corresponding 95\% CI for the associations between ELF score and each component and T2D risks. The final model was adjusted for age at blood-taking (years), education level (primary school and below, secondary or above), fasting status (yes, no), smoking (never, ever smoker), alcohol intake (never, ever drinker), weekly activity ( $<0.5, \geq 0.5$ hours/week), history of hypertension (yes, no), body mass index $\left(\mathrm{kg} / \mathrm{m}^{2}\right)$, triglycerides, high-sensitivity $\mathrm{C}$ reactive protein, highdensity lipoprotein cholesterol, adiponectin, gammaglutamyl transferase and alanine aminotransferase (all in quartiles). The blood biomarkers included in the final model have previously shown to be associated with incident T2D in this population. ${ }^{7-10}$ Potential interaction with age $(<60$ vs $\geq 60$ years), sex, body mass index $(<23$ vs $\geq 23 \mathrm{~kg} / \mathrm{m}^{2}$ ), alcohol consumption (never vs weekly or daily), fasting status and all blood biomarkers (<median vs $\geq$ median levels) were also tested.
Table 1 Baseline characteristics of incident type 2 diabetes cases and matched controls, the Singapore Chinese Health Study*

\begin{tabular}{|c|c|c|c|}
\hline & $\begin{array}{l}\text { Cases } \\
(n=254)\end{array}$ & $\begin{array}{l}\text { Controls } \\
(n=254)\end{array}$ & $\mathbf{P}$ value \\
\hline Age (years) at blood taken & $59.0 \pm 5.83$ & $59.3 \pm 6.03$ & - \\
\hline Gender (female) & $134(52.8)$ & $134(52.8)$ & - \\
\hline Dialect (\%) & & & - \\
\hline Cantonese & $127(50.0)$ & $127(50.0)$ & \\
\hline Hokkien & $127(50.0)$ & $127(50.0)$ & \\
\hline Body mass index $\left(\mathrm{kg} / \mathrm{m}^{2}\right)$ & $24.8 \pm 3.68$ & $22.6 \pm 3.41$ & $<0.001$ \\
\hline Level of education (\%) & & & 0.84 \\
\hline No formal education & $31(12.2)$ & $34(13.4)$ & \\
\hline Primary school & $117(46.1)$ & $111(43.7)$ & \\
\hline Secondary and above & $106(41.7)$ & $109(42.9)$ & \\
\hline History of hypertension (\%) & $127(50.0)$ & $57(22.4)$ & $<0.001$ \\
\hline Cigarette smoking (\%) & & & 0.57 \\
\hline Never smokers & $177(70.0)$ & $178(70.1)$ & \\
\hline Former smoker & $34(13.4)$ & $40(15.8)$ & \\
\hline Current smokers & $43(16.9)$ & $36(14.2)$ & \\
\hline Weekly moderate-to-vigorou & Is activity (\%) & & 0.004 \\
\hline$<0.5$ hours/week & $199(78.4)$ & $196(77.2)$ & \\
\hline $0.5-3.9$ hours/week & 44 (17.3) & $29(11.4)$ & \\
\hline$\geq 4$ hours/week & $11(4.3)$ & $29(11.4)$ & \\
\hline Alcohol intake (\%) & & & 0.95 \\
\hline Abstainers & $223(87.8)$ & $223(87.8)$ & \\
\hline Weekly drinkers & $25(9.8)$ & $24(9.5)$ & \\
\hline Daily drinkers & $6(2.4)$ & $7(2.8)$ & \\
\hline Fasting status (yes) & $75(29.5)$ & $68(26.8)$ & 0.49 \\
\hline ELF score, $\mu \mathrm{g} / \mathrm{L}$ & $9.28 \pm 0.71$ & $9.18 \pm 0.69$ & 0.12 \\
\hline TIMP1, $\mu \mathrm{g} / \mathrm{L}$ & $227.9 \pm 39.0$ & $213.5 \pm 35.6$ & $<0.001$ \\
\hline PIIINP, $\mu g / L$ & $7.56 \pm 2.69$ & $7.01 \pm 2.75$ & 0.023 \\
\hline $\mathrm{HA}, \mu \mathrm{g} / \mathrm{L}$ & $69.6 \pm 67.0$ & $68.8 \pm 76.8$ & 0.90 \\
\hline GGT, IU/L & $31(21-46)$ & $23(17-35)$ & $<0.001$ \\
\hline ALT, IU/L & $25(19-36)$ & $20(15-27)$ & $<0.001$ \\
\hline $\mathrm{HDL}-\mathrm{C}, \mathrm{mmol} / \mathrm{L}$ & $1.08 \pm 0.26$ & $1.23 \pm 0.31$ & $<0.001$ \\
\hline $\mathrm{TG}, \mathrm{mmol} / \mathrm{L}$ & $2.1(1.4-2.8)$ & $1.5(1.0-2.0)$ & $<0.001$ \\
\hline Adiponectin, $\mu \mathrm{g} / \mathrm{mL}$ & $7.26 \pm 3.01$ & $9.09 \pm 3.57$ & $<0.001$ \\
\hline hs-CRP, mg/L & $1.6(0.9-3.2)$ & $1.2(0.6-2.1)$ & $<0.001$ \\
\hline $\mathrm{HbA1c}, \%$ & $5.90 \pm 0.35$ & $5.53 \pm 0.27$ & $<0.001$ \\
\hline
\end{tabular}

${ }^{*}$ Data are expressed as mean $\pm S D$ for continuous variables (normally distributed) and median (IQR) for continuous variables (skewed distributed), and $\mathrm{n}$ (percentage) for categorical variables. Cases and controls are matched on age at blood taken ( \pm 3 years), gender, dialect and date of blood collection ( \pm 6 months).

tP values based on the $\chi^{2}$ test for categorical variables, student's t-test for continuous variable with normal distribution and Mann-Whitney $\mathrm{U}$ test for continuous variable with skewed distribution.

ALT, alanine aminotransferase; ELF, enhanced liver fibrosis; GGT, gammaglutamyl transferase; HA, hyaluronic acid; HbA1c, hemoglobin A1c; HDL-C, high-density lipoprotein cholesterol; hs-CRP, high-sensitivity $C$ reactive protein; PIIINP, amino-terminal propeptide of type III procollagen; TG, triglycerides; TIMP1, tissue inhibitor of matrix metalloproteinase 1.

\section{RESULTS}

Baseline characteristics of cases and controls are shown in table 1 . Among the 254 T2D cases, the mean duration 
between blood-taking and T2D diagnosis for cases was 4.0 (SD 1.7) years. The mean age at blood-taking was 59.1 (SD 5.93) years and 134 (52.8\%) were women. Compared with controls, cases with T2D tended to have higher body mass index and lower levels of weekly moderateto-vigorous activity, and were more likely to have history of hypertension. In addition, cases had higher levels of gamma-glutamyl transferase, alanine aminotransferase, triglycerides, high-sensitivity $\mathrm{C}$ reactive protein and HbAlc, as well as lower levels of adiponectin and highdensity lipoprotein cholesterol compared with controls. The mean levels of ELF score were not statistically different between cases and controls, and the respective values were 9.28 (SD 0.71) and 9.18 (SD 0.69; $\mathrm{p}=0.12$ ). Among the three components of ELF score, mean levels of TIMP1 (227.9 (SD 39.0) $\mu \mathrm{g} / \mathrm{L}$ in cases vs 213.5 (SD 35.6) $\mu \mathrm{g} / \mathrm{L}$ in controls; $\mathrm{p}<0.001$ ) and PIIINP (7.56 (SD
2.69) $\mu \mathrm{g} / \mathrm{L}$ in cases vs $7.01(\mathrm{SD} 2.75) \mu \mathrm{g} / \mathrm{L}$ in controls; $\mathrm{p}=0.023$ ) were statistically higher in cases than controls. However, levels of HA were similar between cases and controls (69.6 (SD 67.0) $\mu \mathrm{g} / \mathrm{L}$ in cases vs 68.8 (SD 76.8) $\mu \mathrm{g} / \mathrm{L}$ in controls; $\mathrm{p}=0.90$ ) (table 1 ).

In the basic model with adjustment of age, education levels and fasting status, the ELF score was not significantly associated with incident T2D risk (table 2); among the three components, TIMP1 and PIIINP were significantly associated with incident T2D risk, while HA was not (table 2). After further adjustment for demographic and lifestyle factors, the TIMP1-T2D association remained significant while the PIIINP-T2D association attenuated to null; the OR comparing extreme quartiles of TIMP1 was 2.76 (95\% CI 1.46 to 5.21; p trend $=0.006)$, and it was $1.50(0.82-2.74 ; \mathrm{p}$ trend $=0.15)$ for PIIINP. After additional adjustment for other blood

Table 2 ORs (95\% Cls) of type 2 diabetes associated with quartiles of ELF score, TIMP1, PIIINP and HA, the Singapore Chinese Health Study

\begin{tabular}{|c|c|c|c|c|c|c|}
\hline \multirow[b]{2}{*}{ Variables } & \multicolumn{4}{|c|}{ Quartiles of variables } & \multirow{2}{*}{$\begin{array}{l}\text { P for } \\
\text { trend* }\end{array}$} & \multirow[b]{2}{*}{ Per SD increment } \\
\hline & Q1 & Q2 & Q3 & Q4 & & \\
\hline \multicolumn{7}{|l|}{ ELF score $†$} \\
\hline Median (range) & $8.51(7.47-8.75)$ & $8.95(8.75-9.12)$ & $9.29(9.13-9.51)$ & $9.92(9.52-12.2)$ & & \\
\hline Case/controls & $63 / 64$ & $53 / 63$ & $50 / 64$ & $88 / 63$ & & \\
\hline Model 1‡ & 1.00 & 0.88 (0.51 to 1.49$)$ & 0.87 (0.49 to 1.54$)$ & $1.54(0.90$ to 2.61$)$ & 0.08 & 1.19 (0.98 to 1.45$)$ \\
\hline Model $2 \S$ & 1.00 & 0.87 (0.47 to 1.60$)$ & 0.72 (0.37 to 1.39$)$ & 1.03 (0.56 to 1.92$)$ & 0.94 & 1.03 (0.83 to 1.29$)$ \\
\hline Model 3ף & 1.00 & 0.88 (0.44 to 1.76$)$ & $0.76(0.37$ to 1.56$)$ & 0.79 (0.38 to 1.62$)$ & 0.46 & $0.92(0.71$ to 1.20$)$ \\
\hline \multicolumn{7}{|l|}{ TIMP1, $\mu \mathrm{g} / \mathrm{L}$} \\
\hline Median (range) & $176(136-186)$ & 199 (187-209) & $221(210-235)$ & $258(236-406)$ & & \\
\hline Case/controls & $32 / 64$ & $56 / 63$ & $66 / 64$ & $100 / 63$ & & \\
\hline Model 1‡ & 1.00 & 1.85 (1.05 to 3.27$)$ & 2.08 (1.17 to 3.68$)$ & 3.02 (1.75 to 5.23$)$ & $<0.001$ & $1.46(1.21$ to 1.76$)$ \\
\hline Model 2§ & 1.00 & 2.21 (1.16 to 4.22$)$ & 2.09 (1.10 to 3.96$)$ & $2.76(1.46$ to 5.21$)$ & 0.006 & $1.42(1.14$ to 1.77$)$ \\
\hline Model 3ף & 1.00 & 2.38 (1.15 to 4.90$)$ & 2.27 (1.09 to 4.75$)$ & 2.56 (1.23 to 5.34$)$ & 0.035 & 1.36 (1.06 to 1.75$)$ \\
\hline \multicolumn{7}{|l|}{ PIIINP, $\mu g / L$} \\
\hline Median (range) & $4.95(3.10-5.40)$ & $5.90(5.50-6.30)$ & $7.00(6.40-7.90)$ & $9.60(8.00-28.5)$ & & \\
\hline Case/controls & $48 / 70$ & $44 / 58$ & $77 / 64$ & $85 / 62$ & & \\
\hline Model 1‡ & 1.00 & 1.16 (0.66 to 2.05$)$ & 1.92 (1.13 to 3.27$)$ & $2.08(1.24$ to 3.48$)$ & 0.001 & 1.21 (1.01 to 1.46$)$ \\
\hline Model $2 \S$ & 1.00 & 1.03 (0.54 to 1.95$)$ & 1.20 (0.65 to 2.20$)$ & $1.50(0.82$ to 2.74$)$ & 0.15 & $1.08(0.88$ to 1.33$)$ \\
\hline Model 3ף & 1.00 & $0.92(0.45$ to 1.88$)$ & $0.87(0.43$ to 1.75$)$ & $1.19(0.59$ to 2.41$)$ & 0.57 & $0.99(0.79$ to 1.25$)$ \\
\hline \multicolumn{7}{|l|}{$H A, \mu g / L$} \\
\hline Median (range) & $26.2(10.4-33.2)$ & $41.9(33.4-50.1)$ & $60.1(50.4-76.3)$ & $111(76.4-936)$ & & \\
\hline Case/controls & $70 / 64$ & $52 / 63$ & $61 / 64$ & $71 / 63$ & & \\
\hline Model 1f & 1.00 & 0.74 (0.44 to 1.27$)$ & 0.90 (0.52 to 1.56$)$ & $1.09(0.64$ to 1.84$)$ & 0.57 & $1.03(0.86$ to 1.25$)$ \\
\hline Model $2 \S$ & 1.00 & 0.70 (0.37 to 1.32$)$ & $0.93(0.49$ to 1.76$)$ & $0.82(0.44$ to 1.54$)$ & 0.79 & 0.95 (0.77 to 1.18$)$ \\
\hline Model 3ף & 1.00 & $0.56(0.27$ to 1.15$)$ & 0.90 (0.43 to 1.88$)$ & $0.62(0.30$ to 1.27$)$ & 0.42 & 0.87 (0.65 to 1.15$)$ \\
\hline
\end{tabular}

*Linear trend was tested using the quartiles of ELF score, TIMP1, PIIINP and HA as continuous variables.

$\dagger E L F$ score $=2.278+0.851 \times \ln ($ HA concentration $)+0.751 \times \ln ($ PIIINP concentration) $+0.394 \times \ln ($ TIMP1 concentration).

¥Model 1: adjusted for age at blood-taking (years), education level (primary school and below, secondary or above) and fasting status (yes, no).

§Model 2: model 1 plus smoking (never, ever smoker), alcohol intake (never, ever drinker), weekly activity ( $<0.5, \geq 0.5$ hours/week), history of hypertension (yes, no) and body mass index $\left(\mathrm{kg} / \mathrm{m}^{2}\right)$.

१Model 3: model 2 plus triglycerides, high-density lipoprotein cholesterol, high-sensitivity C reactive protein, adiponectin, gamma-glutamyl transferase and alanine aminotransferase (all in quartiles).

ELF, enhanced liver fibrosis; HA, hyaluronic acid; PIIINP, amino-terminal propeptide of type III procollagen; Q, quartile; TIMP1, tissue inhibitor of matrix metalloproteinase 1. 


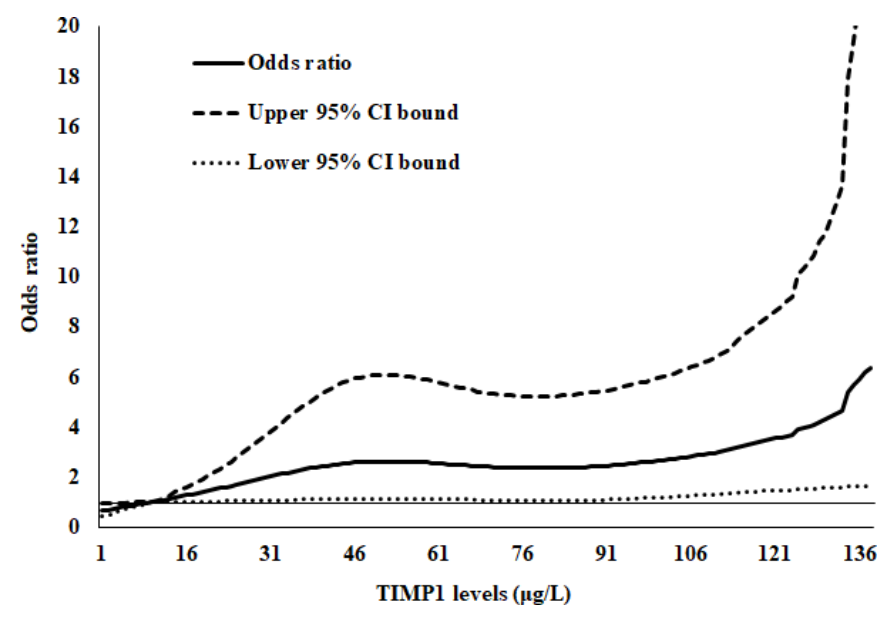

Figure 1 Restricted cubic spline analysis of the association between TIMP1 levels and incident type 2 diabetes. The solid line represents point estimates of relative risk for the association between TIMP1 levels and risk of incident type 2 diabetes, and the dotted lines represent the upper and lower bound of $95 \% \mathrm{Cl}$. Study participants with the highest $5 \%$ of TIMP1 were excluded to minimize the potential impact of outliers. Cubic spline analysis was used to examine the association between TIMP1 concentrations and risk of developing type 2 diabetes using the model 3 from table 2 ( $p$ non-linearity $=0.21$ ). TIMP1, tissue inhibitor of matrix metalloproteinase 1.

biomarkers, the positive association was slightly attenuated but remained statistically significant (OR comparing extreme quartiles of TIMP1: 2.56 (95\% CI 1.23 to 5.34; $\mathrm{p}$ trend $=0.035))$. The restricted cubic spline analysis suggested that the TIMP1-T2D association was linear ( $p$ for non-linearity=0.21) (figure 1). The OR associated with per SD increment of TIMP1 levels for T2D risk was 1.36 (95\% CI 1.06 to 1.75 ) in the final model (table 2). Furthermore, in stratified analyses by baseline characteristics and other biomarkers, the TIMP1-T2D association was similar in the subgroups without significant interactions (data not shown).

\section{DISCUSSION}

In this prospective case-control study nested in a population-based cohort of middle-aged and older Chinese adults in Singapore, we did not find an association between the ELF score and T2D risk. Among the three components, TIMP1 levels were positively associated with diabetes risk; however, both PIIINP and HA were not associated with T2D risk. Therefore, elevated TIMP1 levels may contribute to the later development of incident T2D through pathways not greatly overlapping with liver fibrosis.

Our finding of the positive association between TIMP1 and T2D concur with results from several cross-sectional and case-control studies from Korea (cases $n=80$, controls $\mathrm{n}=80),{ }^{11}$ Iraq (cases $\mathrm{n}=54$, controls $\left.\mathrm{n}=26\right),{ }^{12}$ the UK (cases $\mathrm{n}=86$, controls $\mathrm{n}=63){ }^{13}$ and the USA $(\mathrm{n}=1069) .{ }^{14}$ Although a case-control study in Greece (cases $n=60$, controls $\mathrm{n}=60$ ) has observed lower TIMP1 levels in patients with
T2D compared with controls, ${ }^{15}$ the heterogeneous results could be explained by the different characteristics of patients included in the study. Compared with all other studies, patients in the Greek study were at more advanced stage of T2D and may have received more intensive treatment ${ }^{15}$; the intensified diabetes therapy have shown to decrease TIMP1 levels significantly, ${ }^{13}$ which may explain for the lower TIMP1 levels among patients with diabetes in the Greek study. For PIIINP and HA, evidence is scarce regarding their associations with $\mathrm{T} 2 \mathrm{D}$ risks; therefore, further studies are warranted to validate our findings.

TIMP1 is a biomarker for systemic fibrosis. Excess deposition of extracellular matrix is the hallmark of systemic fibrosis, and TIMP1 promotes fibrosis by inhibiting metalloproteinases in the breakdown of extracellular matrix. ${ }^{16}$ In support of this, epidemiological findings have reported different levels of metalloproteinases, the target enzyme of TIMP1 inhibition, between people with and without T2D. ${ }^{11-13}$ TIMP1 also enhances adipogenesis by accelerating lipid accumulation and adipocyte differentiation, ${ }^{17}$ and this process results in the rapid expansion of adipose tissues, which in turn contributes to subsequent hypoxia and inflammation in the adipose tissues, and further aggravating adipose tissue fibrosis. ${ }^{18}$ Hence, TIMP1 could be implicated in the pathogenesis of T2D by its role in adiposity, systemic fibrosis and inflammation, which have all been shown to be associated with metabolic disturbances and resulting in insulin resistance. $^{19}$

To our best knowledge, this is the first prospective study investigating the association between ELF score and T2D risk. The exclusion of undiagnosed diabetes in cases at the time of blood-taking using HbAlc as diagnostic criteria is a strength of the current study in establishing temporality in the association. We also excluded possible undiagnosed diabetes among controls by using stringent HbAlc criteria at the time of blood-taking. However, several limitations merit consideration. First, residual confounding may exist since height and weight were self-reported in the current study, and some major T2D risk factors, such as family history of T2D, ${ }^{20}{ }^{21}$ fasting levels of glucose and insulin and inflammatory markers $\left(\mathrm{eg}\right.$, IL- $\left.66^{22}\right)$, were not available in the current study due to lack of information. We did not collect the information on family history of T2D because the current cohort was initially established for cancer research. In addition, about two-thirds of the blood samples were non-fasted. However, we stratified the analysis by fasting status and observed similar TIMP1-T2D associations in both subgroups, suggesting that the fasting status is unlikely to affect the observed association. The current study was conducted among middle-aged and elderly population, and generalisability to younger population is a concern, although no significant interaction was found with age. Furthermore, the current study had a relatively short follow-up time of about 4 years; future studies with longer follow-up durations are warranted to examine the predictive performance of TIMP1 for the long-term T2D risk. 
In conclusion, in this case-control study nested within a prospective cohort among Chinese living in Singapore, we found no significant association between the ELF score and T2D risk, but a positive association between TIMP1 and T2D risk. Our results suggested that elevated TIMP1 levels may contribute to the T2D development through pathways other than liver fibrosis. Future studies are warranted to validate the current finding and to elucidate the underlying mechanism to facilitate the development of drugs and therapies targeting TIMP1 levels for the prevention and management of T2D risk.

Acknowledgements The authors would like to thank Siew-Hong Low of the National University of Singapore for supervising the fieldwork of the Singapore Chinese Health Study, and Renwei Wang for the maintenance of the cohort study database. The authors would also like to thank the founding principal investigator of the Singapore Chinese Health Study, Mimi C. Yu.

Contributors AP and W-PK conceived the study, interpreted the data and critically revised the reports. YW did the search, analyzed and interpreted the data, drafted and critically revised the reports. J-MY contributed to the acquisition of study materials and critically revised the reports. All authors revised and approved the final report.

Funding This work was supported by the National Medical Research Council, Singapore (NMRC/CIRG/1354/2013) and National Institutes of Health, USA (R01 CA144034 and UM1 CA182876). AP is supported by the National Key Research and Development Program of China (2017YFC0907504).

Competing interests None declared.

Patient consent for publication Not required.

Ethics approval The study protocol was approved by the Institutional Review Boards at the National University of Singapore and the University of Pittsburgh (NUSIRB Ref Code: 06-027).

Provenance and peer review Not commissioned; externally peer reviewed.

Data availability statement Data are available on reasonable request from corresponding author

Open access This is an open access article distributed in accordance with the Creative Commons Attribution Non Commercial (CC BY-NC 4.0) license, which permits others to distribute, remix, adapt, build upon this work non-commercially, and license their derivative works on different terms, provided the original work is properly cited, appropriate credit is given, any changes made indicated, and the use is non-commercial. See: http://creativecommons.org/licenses/by-nc/4.0/.

\section{ORCID iD}

Yeli Wang http://orcid.org/0000-0003-3031-6199

\section{REFERENCES}

1 Mantovani A, Byrne CD, Bonora E, et al. Nonalcoholic fatty liver disease and risk of incident type 2 diabetes: a meta-analysis. Diabetes Care 2018;41:372-82.

2 Rosenberg WMC, Voelker M, Thiel R, et al. Serum markers detect the presence of liver fibrosis: a cohort study. Gastroenterology 2004;127:1704-13.
3 Nobili V, Parkes J, Bottazzo G, et al. Performance of ELF serum markers in predicting fibrosis stage in pediatric non-alcoholic fatty liver disease. Gastroenterology 2009;136:160-7.

4 The National Institute for Health and Care Excellence. Non-Alcoholic fatty liver disease (NAFLD): assessment and management, 2016. Available: https://www.nice.org.uk/guidance/ng49/chapter/ recommendations/; [Accessed 10 Sept 2019].

5 Smith BW, Adams LA. Nonalcoholic fatty liver disease and diabetes mellitus: pathogenesis and treatment. Nat Rev Endocrinol 2011;7:456-65.

6 Hankin JH, Stram DO, Arakawa K, et al. Singapore Chinese Health study: development, validation, and calibration of the quantitative food frequency questionnaire. Nutr Cancer 2001;39:187-95.

7 Koh W-P, Yuan J-M, Yuan J-M, et al. Association between liver enzymes and incident type 2 diabetes in Singapore Chinese men and women. BMJ Open Diabetes Res Care 2016;4:e000296.

8 Wang Y-L, Koh W-P, Talaei M, et al. Association between the ratio of triglyceride to high-density lipoprotein cholesterol and incident type 2 diabetes in Singapore Chinese men and women. $J$ Diabetes 2017;9:689-98.

9 Pan A, Wang Y, Yuan J-M, et al. High-Sensitive C-reactive protein and risk of incident type 2 diabetes: a case-control study nested within the Singapore Chinese Health study. BMC Endocr Disord 2017;17:8.

10 Wang Y, Meng R-W, Kunutsor SK, et al. Plasma adiponectin levels and type 2 diabetes risk: a nested case-control study in a Chinese population and an updated meta-analysis. Sci Rep 2018;8:406.

11 Lee SW, Song KE, Shin DS, et al. Alterations in peripheral blood levels of TIMP-1, MMP-2, and MMP-9 in patients with type-2 diabetes. Diabetes Res Clin Pract 2005;69:175-9.

12 Wadood SA, Shawk RA, Hashem R. Variants of MMP-9 and TIMP-1 levels could be a predictor of an early development of cardiovascular diseases in type 2 diabetes among Iraqi patients. Iraqi J Sci 2015;56:622-32.

13 Tayebjee MH, Lim HS, MacFadyen RJ, et al. Matrix metalloproteinase- 9 and tissue inhibitor of metalloproteinase- 1 and -2 in type 2 diabetes: effect of 1 year's cardiovascular risk reduction therapy. Diabetes Care 2004;27:2049-51.

14 Sundström J, Evans JC, Benjamin EJ, et al. Relations of plasma total TIMP-1 levels to cardiovascular risk factors and echocardiographic measures: the Framingham heart study. Eur Heart J 2004;25:1509-16.

15 Papazafiropoulou A, Perrea D, Moyssakis I, et al. Plasma levels of MMP-2, MMP-9 and TIMP-1 are not associated with arterial stiffness in subjects with type 2 diabetes mellitus. $J$ Diabetes Complications 2010;24:20-7.

16 Bonnans C, Chou J, Werb Z. Remodelling the extracellular matrix in development and disease. Nat Rev Mol Cell Biol 2014;15:786-801.

17 Alexander CM, Selvarajan S, Mudgett J, et al. Stromelysin-1 regulates adipogenesis during mammary gland involution. $J$ Cell Biol 2001;152:693-703.

18 Buechler C, Krautbauer S, Eisinger K. Adipose tissue fibrosis. World J Diabetes 2015;6:548-53.

19 Sun K, Tordjman J, Clément K, et al. Fibrosis and adipose tissue dysfunction. Cell Metab 2013;18:470-7.

20 InterAct Consortium, Scott RA, Langenberg C, et al. The link between family history and risk of type 2 diabetes is not explained by anthropometric, lifestyle or genetic risk factors: the EPIC-InterAct study. Diabetologia 2013;56:60-9.

21 Qi Q, Li H, Wu Y, et al. Combined effects of 17 common genetic variants on type 2 diabetes risk in a Han Chinese population. Diabetologia 2010;53:2163-6.

22 Pradhan AD, Manson JE, Rifai N, et al. C-Reactive protein, interleukin 6 , and risk of developing type 2 diabetes mellitus. JAMA 2001;286:327-34. 